\title{
O direito como regulador do discurso ideológico da fraternidade em uma sociedade pós-liberal
}

Adilson Silva Ferraz ${ }^{*}$

\footnotetext{
Doutorando em Direito, Universidade de Buenos Aires (UBA). Professor assistente da Faculdade ASCES, assistente da Faculdade de Filosofia, Ciências e Letras de Caruaru (FAfICA) e Auxiliar de II, Universidade de Buenos Aires (UBA), Buenos Aires, Argentina. Correo electrónico: adilsonferraz@asces.edu.br
}

Recibido: 14 de noviembre del 2014 Aprobado: 4 de abril del 2015

Cómo citar este artículo: Adilson Silva Ferraz. 0 direito como regulador do discurso ideológico da fraternidade em uma sociedade pós-liberal. DIXI 21. Junio de 2015. Pág. 27. doi: http://dx.doi.org/10.16925/ di.v17i21.977

\section{Resumo}

O objetivo deste artigo é demonstrar que há um abismo entre a fraternidade em seu sentido utópico (ideal) e seu sentido prático (real). O sentido utópico é frequentemente tomado como fundamento do sentido prático e pode ser manipulado discursivamente para qualquer fim prático, inclusive contra os direitos humanos. Denominamos isso de "discurso ideológico da fraternidade". Para isso, explicamos que a fraternidade existe dialeticamente e é retoricamente definida como outros fenômenos. A dialética explica a fraternidade a partir da ideia de "abertura fraterna", um fenômeno existencial que atua no reconhecimento mútuo entre os sujeitos e na ressignificação da alteridade. Em seguida, apresentamos a tese principal: a inclusão da fraternidade como elemento jurídico pode ajudar a impedir o discurso ideológico do próprio direito (quando este se volta contra os direitos fundamentais) e servir como barreira de contenção ao discurso ideológico da fraternidade moral, embora haja sempre o risco de esta ser utilizada para aprofundar o abismo entre a utopia e a prática tornando-se um mecanismo jurídico de opressão social.

Palavras-chave: direito, fraternidade, ideologia, moral, utopia. 


\title{
El derecho como regulador del discurso ideológico de la fraternidad en una sociedad posliberal
}

\section{Resumen}

Este artículo tiene como fin demostrar que hay un abismo entre la fraternidad en su sentido utópico (ideal) y su sentido práctico (real). El sentido utópico es a menudo tomado como fundamento del sentido práctico y puede manipularse discursivamente para cualquier fin práctico, incluso en contra de los derechos humanos. Lo denominamos como "discurso ideológico de la fraternidad". Para ello, explicamos que la fraternidad existe dialécticamente y se define retóricamente como otros fenómenos. La dialéctica explica la fraternidad a partir de la idea de "apertura fraterna", un fenómeno existencial que actúa en el reconocimiento mutuo entre los sujetos y en la resignificación de la alteridad. Luego, presentamos la tesis principal: la inclusión de la fraternidad como elemento jurídico puede ayudar a impedir el discurso ideológico del propio derecho (cuando este se vuelve en contra de los derechos fundamentales) y servir como barrera de contención al discurso ideológico de la fraternidad moral, si bien hay siempre el riesgo de esta de ser utilizada para profundizar el abismo entre la utopía y la práctica, al volverse un mecanismo jurídico de opresión social.

Palabras clave: derecho, fraternidad, ideología, moral, utopía.

\section{The Law as Regulator of the Ideological Discourse of Fraternity in a Post-Liberal Society}

\begin{abstract}
This text aims to show that there is a gap between fraternity in its utopian (ideal) sense and its practical (real) sense. The utopian sense is customarily used as the basis for the practical sense and can discursively be manipulated for any practical purpose, even against human rights. We call this the "ideological discourse of fraternity". We explain that fraternity exists dialectically and is defined rhetorically like other phenomena. The dialectic explains fraternity based on the idea of "fraternal openness", and a special phenomenon that acts in the mutual recognition between individuals and in the resignification of otherness. We then present the main thesis: the inclusion of fraternity as a legal element that can help to prevent the ideological discourse of law itself (when this is turned against fundamental rights) and serve as a barrier of containment for the ideological discourse of moral fraternity, even though there is always the risk that this may be used to deepen the gap between utopia and practice, by becoming a legal mechanism for social oppression.
\end{abstract}

Keywords: law, fraternity, ideology, moral, utopia. 


\section{INTRODUÇÃO}

Será que podemos imaginar para o século XXI uma superação do capitalismo que seja ao mesmo tempo mais pacífica e mais duradoura, ou deveríamos esperar pelas próximas crises ou pelas próximas guerras, verdadeiramente mundiais desta vez ? $^{1}$

O neologismo "neoliberalismo" já era usado pelo New York Times em 1939 para designar a proposta de um novo modelo político-econômico, que passaria a ser programa de Estado na década de setenta. Entretanto, o termo tornou-se realmente usual apenas na década de noventa. Hoje, já falamos de "pós-neoliberalismo", de modo que seu significado precisa ser esclarecido. Podemos entender o conceito basicamente de três formas: a) como uma etapa historicamente posterior ao neoliberalismo; b) como uma etapa de aprofundamento das práticas neoliberais; c) como etapa que supera o (neo)liberalismo.

A primeira definição é vazia no sentido de explicar o advento de um novo momento histórico. Não se refere a uma escola de pensamento ou a um novo modelo de Estado e sociedade, mas ao fato de que se esgotou um momento anterior e que este foi substituído por outro. É o sentido, por exemplo, de quando falamos "O capitalismo foi possível somente no período pós-Idade Média." ou "Ela se recupera bem do pós-parto." Revela o post que se opõe ao prae. O segundo sentido acarreta algumas dificuldades. Se há aprofundamento do neoliberalismo, não faz sentido falar em um pós-neoliberalismo, a não ser que as suas características principais beirem um novo sistema e, nesse caso, o termo já não se referiria mais ao modelo anterior nem serviria de elo linguístico de transição que permite falar de algo diferente que não se conhece bem ainda. É o caso muitas vezes do uso do termo pós-modernidade. Os três sentidos são possíveis, mas é o terceiro que nos interessa mais, pois se refere à possível emergência de modelos que venham a substituir o (neo)liberalismo. O último sentido subsome o primeiro de alguma forma. O pós-neoliberalismo, portanto, entendido nesse último sentido, reivindica um caráter inovador e superador das contradições (neo)liberais. Assim, seria o pós-neoliberalismo um aprofundamento do (neo)liberalismo ou o anúncio de seu fracasso?

1. Thomas Piketty. O CAPITAL No sÉculo XXI. Intrínseca. (2014). Pág. 459.
Nas últimas décadas, tem ocorrido processos de integração regional, uma crescente tensão entre ocidente e oriente, a flexibilização do trabalho, o despertar da sociedade civil por mais participação, crise financeira global, e outros fenômenos que desafiam o neoliberalismo. Aparentemente não tem funcionado tão bem a ideia de que os mercados se autocorrigem, alocam recursos de forma adequada e servem aos interesses públicos. Isso nos faz pensar se existe realmente um "pós" ou se estas são as consequências do espírito resiliente de uma época. Assim como Piketty, perguntamo-nos se o sistema atual será superado ou se devemos esperar novas crises e guerras. Peck, Theodore e Brenner (2012) afirmam que, enquanto crises anteriores da era neoliberal (como o descumprimento da dívida por países da América Latina e o colapso financeiro asiático) podem ter sido "administradas" por meio de uma série de ajustes de percurso na governança, discurso e estratégia neoliberais, a crise atual ameaça, talvez fatalmente, minar a legitimidade política do neoliberalismo. Devemos perceber, no entanto, que o neoliberalismo é dinâmico, de modo que é muito provável que não surja um novo modelo puro. Como ressalta Emir Sader, em seu livro Refundar el Estado. Posneoliberalismo en Americalatina:

América Latina fue el laboratorio de experiencias neoliberales, región en la cual nació el modelo, pero se extendió y asumió sus formas más radicales. Por lo tanto comenzó a sufrir una resaca neoliberal y a constituir un eslabón más débil de la cadena neoliberal, en donde más proliferan los Gobiernos elegidos en el seno del rechazo al neoliberalismo, a contramano de las tendencias mundiales. ${ }^{2}$

Afirma também que existe "un debilitamiento del modelo neoliberal en el mundo, pero no hay ningún modelo alternativo que dispute con él."3 Existiria um modelo pós-neoliberal (no terceiro sentido) desejável? Nesse contexto complexo, perguntamo-nos se vínculos sociais distintos aos construídos frequentemente no ambiente neoliberal poderiam combater fenômenos como pobreza, corrupção, falta de participação, desigualdade social, alienação e clientelismo no âmbito da política.

2. Emir Sader. Refundar el Estado. Posneoliberalismo en AmÉrica latina. Instituto de Estudios y Formación de la CTA. (2008). Pág. 77.

3. Id. Pág. 10. 
Que tipo de coesão social seria mais benéfico para a construção de uma sociedade mais justa? Qual o melhor modelo de política? É a pergunta a que tentam responder algumas teorias da fraternidade desenvolvidas nas últimas décadas. Chiara Lubich, fundadora do movimento focolare, e Enrique Del Percio, professor da Universidade de Buenos Aires (UBA), criaram as duas principais propostas teóricas acerca de uma sociedade fraterna. Estudos como estes seriam importantes em função do atual esvaziamento ético apontado por João Maurício Adeodato: ${ }^{4}$

As democracias vivem a partir da domesticação da intolerância, pois democracia significa inclusão, regras comuns, reconhecimento do outro, fragmentação do poder. Pressupõe também certa desconfiança para com o caráter humano, sua autoindulgência, sua vaidade. Como sistema político, a democracia procedimentaliza os meios de decisão e os esvazia de conteúdo ético $[\ldots]$

Neste texto, objetivamos partir dessas duas teorias e problematizar o uso da ideia de fraternidade como mecanismo retórico de ação, além de buscarmos entender sua relação com o direito. A seguir, trataremos das duas teorias anteriormente citadas.

\section{A FUNDAMENTAÇÃO DA POLÍTICA}

\section{NA TEOLOGIA DA FRATERNIDADE UNIVERSAL DE CHIARA LUBICH ${ }^{5}$}

Fazer-se um é o verdadeiro realismo político.

Nos entendemos que nosso movimento surgiu para preencher esta parte do evangelho. Que "todos" seria nosso campo de ação, e unidade e nossa razão de ser. Fazendo isto, o sonho de Deus, nossa própria ligação com o céu. Ao mesmo tempo, ele está inserido na história da humanidade, para desvelar o caminho em direção à irmandade universal. ${ }^{6}$

4. João Maurício Adeodato. A Retórica Constitucional - soBRE TOLERÂNCIA, DIREITOS HUMANOS E OUTROS FUNDAMENTOS ÉTICOS Do DiReito Positivo. Saraiva. (2009). Pág. 74.

5. Chiara Lubich é a fundadora do movimento dos Focolares. Nasceu em 22 de janeiro de 1920, em Trento, morreu em 14 de março de 2008.

6. Chiara Lubich. Essential writings. Spirituality. Dialogue. Culture. New City Press. (2007). Pág. 266.
Bertrand Russell ${ }^{7}$ está correto quando afirma em seu ensaio Psicologia e Política que nem sempre as opiniões políticas se baseiam na razão. Mesmo um assunto tão técnico como o padrão-ouro teria sido determinado fundamentalmente por sentimentos. A questão é saber se um sentimento específico deve servir de base para a política e qual seria o melhor sentimento para essa tarefa. Campello ${ }^{8}$, por exemplo, em seu texto Política e Amor: revendo uma relação difícil, afirma que é uma vantagem associar a política não somente com a racionalidade e a forma. Seria necessário entendê-la como uma dimensão constitutiva do ser humano, em que paixões, desejos e afetos cumprem um papel fundamental.

Esta parece ser a proposta de Chiara Lubich quando fala em fraternidade; um conceito que desde sua origem esteve ligado de alguma forma ao aspecto não racional das relações humanas. Seu pensamento não constitui uma ciência ou teoria em sentido estrito, senão uma teologia cristã que propõe uma ética aplicada e um modelo de sociedade. A fraternidade, segundo a proposta de Lubich, resumida nas palavras de Maria Voce: "[...] poderia constituir um princípio de fundo útil, ou talvez indispensável (acreditam os focolarinos), para reformular política e economia, comunicação e educação, ética e cultura". ${ }^{9}$ Como podemos observar, a fraternidade seria um princípio "guarda-chuva" segundo o qual as mazelas do mundo poderiam ser desfeitas. Seguindo essa perspectiva, a fraternidade teria sido esquecida no período moderno ${ }^{10}$ o que provocou uma distorção na tríade da revolução francesa já que, somente em uma sociedade fraterna, a igualdade e a liberdade poderiam ser verdadeiramente vividas. Seria preciso resgatar a fraternidade, enquanto ideal, elemento interno ao homem e como prática social que levaria à paz mundial:

A fraternidade é capaz de dar fundamento à ideia de uma comunidade universal, de uma unidade de diferentes, na qual os povos vivam em paz entre si, sem o jugo de um tirano, mas no respeito das próprias

7. Bertrand Russell. Ensaios cÉTICOS. Porto Alegre: L \& PM. (2014). Pág. 186.

8. Marconi Andrade Silva, Fernando Gomes Andrade, Paulo Muniz Lopes (Orgs.). CidAdania, PARTICIPAÇÃo E FRATERNIDAdE - UMA ABORdAgEM MUlTidisciplinar. Editora UfPe. (2014). Pág. 13. 9. Maria Voce. Desafios. Cidade Nova. (2014). Pág. 101. 10. Antônio Maria Baggio (Org.). O Princípio Esquecido: EXIGÊNCIAS, RECURSOS E DEFINIÇÕES DA FRATERNIDADE NA POLÍTICA. Cidade Nova. (2008). Pág. 33. 
identidades. E justamente por isso a fraternidade é perigosa. Descobrimos que somos livres e iguais porque somos irmãos. ${ }^{11}$

Esta não é a perspectiva adotada por Jean-Luc Ferry ${ }^{12}$ quando afirma que "[...] o segundo humanismo é da emoção e da afetividade." Segundo o francês, vivemos um momento histórico, o segundo humanismo, que tem como principal característica o amor. Não o amor a um Deus, a uma pátria ou a uma grande causa, mas o amor das relações cotidianas que dariam sentido à nossa existência. Lubich, de modo bem distinto, defende o resgate do amor nas relações humanas, mas sob uma perspectiva cristã, com pretensões ecumênicas. Podemos citar como principais características da teologia universal de Lubich: 1) é uma teologia cristã, na medida em que estaria inserida em sua história (o movimento focolare surge a partir de um "carisma da unidade") e utiliza seus conceitos; 2) é normativa pois dá diretrizes para o agir; 3) é programática já que propõe um modelo de sociedade a ser alcançado; 4) é kantiana (ainda que não expressamente) ao se pautar na pretensão de universalidade e cosmopolitismo; 5) é antropológica, ao descrever o humano; 6) é um movimento político; 7) baseia-se no conceito de "humanidade"; 8) é expansionista, ao se utilizar do conceito de "inundações"; 9) apresenta-se por meio de uma origem espiritual ou divina; 10) está inserida em um contexto de determinismo escatológico; 11) é organicista pois entende a sociedade partindo do indivíduo, em direção à família, povo, humanidade, Deus, como um grande organismo. Não é nosso objetivo neste trabalho explicar cada um desses pontos, mas sim apresentá-los como elementos importantes para a compreensão do modelo de sociedade proposto por Chiara Lubich, que superaria a fragmentação atual. Sobre a unidade, Lubich $^{13}$ esclarece em seu texto Pessoas em Comunhão que:

Nós temos vivido o poder de educar, de oferecer alternativas, do desafio destas palavras, que é sempre vivo e sempre novo. Passo a passo, como foi imprimido [sic] em nossas vidas, e foi dada a elas (e essa é a tremenda tarefa da educação) uma unidade existencial. Esta unidade nos ajuda a superar a fratura e a fragmen-

11. Id. Pág. 53.

12. Jean-Luc Ferry. A RevoluÇão do AMOR: POR UMA ESPIRITUalidade laica. Trad. Véra Lucia dos Reis. Objetiva. (2012). Pág. 123.

13. Lubich, supra, nota 6. Pág. 227. tação que as pessoas têm frequentemente vivido em relação a elas mesmas, aos outros, com a sociedade, a Deus, que ao mesmo tempo desenha a originalidade, e a irrepetível univocidade de cada um.

De acordo com essa visão resumida anteriormente, a política não nasce do temor ao inimigo (é uma criação interior e exterior, na forma de uma pessoa, grupo, comunidade estrangeira etc.), mas pelo amor ao amigo, e a principal causa da existência de uma falsa política seria a alienação (econômica, cultural etc.) e a incapacidade de doar-se. Na verdadeira política não há fim que justifique como meio um ato de inimizade já que nela todo meio deve ser bom em si mesmo. Defini-la em função do inimigo criaria o inimigo, e a guerra significaria seu fracasso. A verdadeira política seria uma via de aperfeiçoamento, que promoveria um diálogo entre a sociedade. Nesse modelo de política, chamado de "política da unidade", existiriam os políticos que participam por um ideal, de modo altruísta, e não por conveniência. A base social para a unidade seria o amor recíproco e a fraternidade o motor que lhe gera, e liberta os indivíduos da pressão dos interesses privados canalizando-os para a prática do bem comum. Segundo Lubich, ${ }^{14}$ o cumprimento do eterno desejo de Deus se baseia no amor fraterno, que é encontrado neste mandamento: "Eu vos dou um novo mandamento, que vos amem uns aos outros." Desse modo, a fraternidade seria uma condição para a existência da verdadeira política. No quadro 1 há uma síntese da passagem da falsa política a uma verdadeira política com o modo pelo qual é realizado o processo de mudança.

Quadro 1. Passagem da velha à nova política

\begin{tabular}{|l|l|l|}
\hline \multicolumn{1}{|c|}{ Diversidade } & \multicolumn{1}{c|}{ Unidade } & \multicolumn{1}{c|}{ Modo } \\
\hline Real & Ideal & Adequação \\
\hline Indivíduo & Humanidade & Convergência \\
\hline Egoísmo & Altruísmo & Transformação \\
\hline Particular & Universal & Convergência \\
\hline Conflito & Paz & Transformação \\
\hline
\end{tabular}

Fonte: elaboração própria

Há adequação quando o parâmetro é alcançado; nesse caso, a unidade é atingida quando o real alcança ou se encaixa com o ideal. Com a convergência é diferente pois o indivíduo não se dissolve

14. Id. Pág. 81. 
na humanidade, mas sim conserva suas características. Igualmente ocorre com a convergência entre particular e universal, na medida em que o particular é particular no universal. Já com a transformação, o que ocorre é uma mudança na natureza do fenômeno. O egoísmo deixa de ser o que é para ser altruísmo. O mesmo ocorre com o conflito, que vira paz. Entretanto, não devemos entender essas mudanças de forma dual. Lubich acredita em um mundo que reflete a natureza divina, que seria sempre ternário. Desse modo, a política verdadeira seria uma expressão autêntica do sagrado e uma etapa de realização da criação. Esta é, em linhas gerais, uma fundamentação da política segundo a religião, na versão cristã apresentada por Lubich.

\section{FRATERNIDADE E CONFLITO NA filosofia de EnRique Del Percio}

[...] la fraternidad también nos muestra que, si bien los Hermanos muchas veces se pelean, no siempre se matan. A veces, los Hermanos se toleran, se resignan a aceptarse y hasta, en ocasiones, se quieren entrañablemente. E incluso, pueden pelearse y quererse por igual. Este carácter ambiguo puede molestar al intelectual acostumbrado a trabajar con esencias y conceptos claros y distintos. ${ }^{15}$

Para Enrique Del Percio, em seu livro Ineludible Fraternidad, que pode ser traduzido como Fraternidade Inescapável, a fraternidade é um dado antropológico não reconhecido pela grande maioria dos teóricos. O que isso quer dizer? Que podemos falar da fraternidade no sentido descritivo, mas o emprego mais frequente é no sentido normativo, que indica o desejo que os frates se gostem, que se deem bem. ${ }^{16}$ Uma visão antropológica sobre a fraternidade colocaria em realce sua face realista, que olha para a origem e revela seu caráter de luta ou conflito.

[...] en la familia, los padres establecen la verticalidad que tiende a disolver el conflicto. En cambio, en el ámbito público no hay padre ni madre: no hay persona ni grupo que pueda detentar "naturalmente" la función

15. Enrique Del Percio. Ineludible Fraternidad - conflicto, PODER y Deseo. Ciccus. (2014). Pág. 36.

16. Id. Pág. 20. paterna de establecer la ley, ni hay una sociedad-útero en cuyo seno maternal todo antagonismo se disuelve. ${ }^{17}$

Comas devidas diferenças, éa mesma perspectiva basicamente defendida por Alexandre Costa Lima ${ }^{18}$ em seu texto Cidadania Não-liberal e Fraternidade: as contribuições de Arendt e Schmitt, em que destaca o valor do conflito para uma política democrática fraterna. Acredita que, longe de transformar a política em um campo de batalhas, proporciona um exercício positivo da liberdade pública. Essa perspectiva realista contribuiria para um exercício mais efetivo da cidadania, na medida em que os antagonismos são transformados de modo criativo em um ambiente de pluralismo democrático.

Uma das teses principais do livro de Del Percio, que materializa a única filosofia construída até o momento sobre o tema, diz respeito ao fato de que a fraternidade seria uma catacrese, e não uma metáfora: "En retórica, una metáfora a la que falta uno de sus términos o 'lados', no es propiamente una metáfora. Catacresis es la figura retórica que consiste en designar una cosa para que se carece de nombre, usando el nombre de otra cosa. Por ejemplo, los 'brazos' del sillón [...]”. ${ }^{19}$ Entender a fraternidade desse modo permite defini-la sem recorrer a um detalhamento mais extensivo já que não há como fundamentar uma antropologia do humano sem emaranhar-se na metafísica, ao mesmo tempo em que a catacrese é utilizada como chave para entender o fenômeno político.

Outro ponto importante é a relação entre fraternidade e ideologia. A fraternidade poderia devolver a possibilidade de pensar a política como uma construção coletiva de novas ideologias, sempre abertas à experimentação. ${ }^{20} \mathrm{~A}$ política, nesse sentido, é um processo e não uma substância, de modo que a liberdade e a igualdade são produto dessa construção social. Com a fraternidade, a liberdade se tornaria "liberação", que é o caminho para a "justiça social", o correlato da igualdade após ser ressignificada. Essa fraternidade é também universal, a fim de não ser excludente, mas também situada, o que quer dizer que parte das diferenças entre os particulares em vez de universalizar um particular. O universal-situado

\section{Id.}

18. Marconi Andrade Silva, Fernando Gomes Andrade, Paulo Muniz Lopes (Orgs.). Cidadania, Participação e Fraternidade uMA Abordagem MUltidisciplinar. Editora UfPe. (2014). Pág. 85. 19. Enrique Del Percio, supra, nota 15. Pág. 44.

20. Id. Pág. 115. 
dá as bases para uma forma particular de pensar o movimento da história e constitui, segundo o autor, uma proposta ética e epistemológica:

El pensar desde las víctimas pone al resguardo el carácter universal de la fraternidad al distinguirlo de la universalidad imperial propia de la filosofía europea y de ciencias disciplinarias, la que es una universalidad derivada de una particularidad exitosa que niega las otras particularidades. ${ }^{21}$

Dessa forma, a fraternidade permite pensar o universal a partir das particularidades de cada situação, garantir a inclusão dos terceiros (que escapa a relação eu-tu), os outros, os excluídos. Ademais, o reconhecimento da fraternidade como abertura ao conflito liberaria os sujeitos do desejo (desejar viria de de-siderare, liberar-se do destino imposto pelas estrelas) narcisista capitalista:

Pero ¿Quién puede devolver la capacidad de desear? Es decir, “¿quién puede decirle a ese chico o a este pueblo: "tu destino no está escrito, vos podés liberarte de las estrellas, vos podés ser artífice de tu propio destino y no un instrumento de la ambición de nadie"?: la acción política. Una acción política que al asumir el valor de la fraternidad entienda que somos seres humanos, ni totalmente buenos ni totalmente malos $[\ldots]^{22}$

Essa nova concepção de fraternidade resgataria um modelo de política que permitiria que os sujeitos vivessem a vida não como um destino, senão respeitando as diferenças, aceitando o conflito como elemento intrínseco da política, dessacralizando as pessoas e instituições. O quadro 2 sintetiza as principais característica da fraternidade segundo a filosofia de Enrique Del Percio.

Quadro 2. Características da fraternidade na filosofia de Enrique Del Percio

\begin{tabular}{|l|l|}
\hline Quanto à origem & Antropológica \\
\hline Quanto à definição & Catacrese \\
\hline Quanto ao modo de desvelamento & Conflito \\
\hline Quanto à proposta & Proteção às vítimas \\
\hline Quanto à abrangência & Universal-situado \\
\hline Quanto às consequências & Liberação e justiça social \\
\hline
\end{tabular}

Fonte: elaboração própria

21. Id. Pág. 79.

22. Id. Pág. 223.
A fraternidade, realizada na horizontalidade, ocorre pelo fato de não haver verticalidade na condição humana, embora possa existir como produto da interação entre os sujeitos. A fraternidade, segundo essa concepção, ocorre justamente na ausência do pai.

Para continuarmos, após apresentarmos sucintamente a teologia da fraternidade de Chiara Lubich e a Filosofia da fraternidade de Enrique Del Percio, tentaremos reconstruir o conceito de fraternidade a partir de um ponto de vista neutro, no qual tentamos adotar uma perspectiva reflexiva e crítica.

\section{Pensando A FRATERnidade A}

\section{PARTIR DE UM PONTO DE INTERROGAÇÃO}

Segundo o senso comum, fraternidade consiste em uma irmandade/sororidade entre as pessoas, o que implica um modelo de relação calcado no respeito e na horizontalidade. Mas qual o "sentido" da fraternidade? Se o fenômeno existe efetivamente, seria um dado antropológico ou uma construção cultural? É um fenômeno universal ou particular? Há diferenças entre a fraternidade conceitual e sua prática? Muito tem se argumentado em favor de um conceito de fraternidade atrelado à religião, entretanto podemos nos perguntar: poderia ser a fraternidade uma categoria ateológica? Seria uma categoria política? Qual sua relação com o Direito? Um estudo aprofundado do conceito parte necessariamente de uma análise acerca dos problemas fundamentais apontados anteriormente. Sobre o tema, alguém poderia dizer: "- Acaso não sei eu ser fraterno? Onde está a fraternidade senão no meu encontro com o outro?! Na tolerância, no amor, na união, na esperança, no respeito... aí está a fraternidade!" Podemos encontrar na literatura outras características apontadas como inerentes à fraternidade, tais como: empatia, solidariedade, confiança, preocupação, reconhecimento, cuidado. $\mathrm{O}$ que nos causa admiração se investigamos mais a fundo a fraternidade se deve a que uma afirmação sobre o que ela é deixa de ser problemática apenas quando não questionamos uma série de pressupostos. A começar pelo fato de que ser tantas coisas a torna inconsistente. Se ela é tudo isso por que não seria também outras coisas? Já pensou se definíssemos amor como "união, esperança, respeito etc."? Não faria sentido falarmos de fraternidade e amor como duas coisas distintas. Não seria difícil ainda descobrir ou criar novas associações, 
inclusive as negativas, por exemplo, "ser fraterno é não praticar o mal", "ser fraterno é não desrespeitar o irmão", "ser fraterno é não discriminar o outro". Dificilmente alguém discordaria dessas negativas. Mas se fraternidade é realmente tudo isso (amor, união, esperança etc.), estes seriam requisitos para sua existência ou seriam consequências? Haveria alguma situação em que ocorresse fraternidade se um ou mais desses elementos não estivessem presentes? Seria a fraternidade um fenômeno variável? Essa inconsistência que apontamos é mascarada pelo uso cotidiano da linguagem, que dá a impressão de que o conceito é homogêneo, o que não se sustenta se o analisarmos a partir de uma abordagem crítica.

Quando falamos em fraternidade, em geral, não estamos muito preocupados com seu real significado. Tugendhat explica o que pretendemos expressar:

[...] parece que nos encontramos ante un ámbito de conocimiento en el que nuestra ignorancia no se debe a una experiencia defectuosa, sino a que se trata de aspectos de nuestra comprensión que nos resultan demasiado cercanos y obvios. A lo que aspiramos aquí no es a la explicación de algo incomprensible en su facticidad, sino a la clarificación de algo ya comprendido. Y esta clarificación sólo se puede lograr mediante la reflexión sobre nuestra comprensión, no mediante la experiencia. ${ }^{23}$

Não nos perguntamos, por exemplo, sobre o fato de uma proposição sobre o que é fraternidade ser muito diferente de proposições como "o número 12 é par" e "amarelo é uma cor". Fraternidade, em seu sentido corrente, não seria algo puramente abstrato (tal qual um número, objeto mental) tampouco algo unicamente da ordem do fático (tal qual uma cor, propriedade física). Qual a relação entre ideal e real na existência desse fenômeno? Tampouco nos perguntamos sobre a medida da fraternidade. Seria algo mensurável? Parece que sobre a fraternidade temos mais dúvidas que certezas. É por isso que, como ponto de partida, não tomarei a fraternidade como solução (como é tão frequente nos estudos sobre o tema), e sim como um problema. Para isso, é preciso recusar a metodologia de construção de uma história do conceito em favor de uma perspectiva crítica. Acredito que essa abordagem seja vantajosa no sentido de explorar o objeto sem que seu sentido seja pressuposto, ou que

23. Ernst Tugendhat. InTroducción A LA FILOSOFÍA ANALÍTiCA. Gedisa. (2003). Pág. 21 concepções prévias afetem sobremaneira a análise, o que exigiria ainda mais precisão linguística e exatidão dos argumentos.

\section{Desnaturalizando}

\section{A FRATERNIDADE}

Devemos adotar inicialmente uma pergunta norteadora, que põe em xeque a própria ideia de fraternidade e coloca-nos contra a parede se entendemos que a teoria e a prática não devem ser dissociadas: como ser fraterno se não sei o que é fraternidade? Tal contradição nos coloca em uma posição realmente embaraçosa. Se não respondo corretamente à pergunta, ser fraterno equivaleria a jogar futebol sem conhecer as regras do jogo, ou a falar sobre algo que desconheço de forma absoluta. E mais, se levarmos a dúvida realmente a sério, facilmente recairíamos em alguma espécie de relativismo ou ceticismo. Se reconheço que o homem não sabe o que é fraternidade, mas que ela existe como utopia, então ela não seria nada mais que algo do plano ideal (eidos, no sentido platônico) e que, por ser dessa esfera, é algo impraticável em sua essência. Por outro lado, se a pratico, mas não sei o que é a fraternidade, afirmo uma inverdade. Como poderia identificar seu acontecimento se não tenho seu significado como parâmetro? É por isso que é mais fácil explicar a fraternidade a partir do que é considerado moralmente positivo em nossa cultura (como na primeira fala de nosso interlocutor), o que não deixa de ser bastante útil em face de nossas relações de poder - é conveniente ser fraterno.

Mas a dificuldade vai além. No âmbito macro, o problema cognitivo prejudica diretamente uma das decisões políticas fundamentais de toda nação (mas que não tem recebido a devida importância nem mesmo no ocidente, onde o conceito surgiu): a fraternidade deve ser um valor a ser adotado por nossa sociedade? Daí decorrem outras perguntas que atingem um patamar crítico: seria a fraternidade incompatível com a política, entendida como conflito e jogo de interesses? Por que não utilizar a fraternidade como princípio unificador (tal qual Deus, amor ou a raça ariana) para fins de domínio do outro? Não seria a constitucionalização da fraternidade um caminho para a sua deturpação? Daí surge nossa segunda pergunta norteadora: $\mathrm{O}$ que é fraternidade jurídica? Todas essas perguntas são complexas e apontam para a necessidade de delimitar-se o que 
é fraternidade, sob o risco de as respostas se tornarem inócuas. Nesse sentido, alguém poderia argumentar: "- Os fenômenos ocorrem sem necessidade de uma definição prévia e definitiva da teoria. A ciência, por exemplo, tem tentado definir o que é a vida há séculos e, apesar das várias mudanças de entendimento, a vida continua a brotar por todos os lados! Poderia ainda afirmar que devemos considerar aquilo que nos constitui enquanto seres humanos, afinal de contas, todos temos uma intuição (um senso comum) que nos indica a emergência da fraternidade. Seria preciso reconhecer que o seu conhecimento não exclui uma relativa ignorância, e que este é o seu modo específico de existência, assim como o de fenômenos como o amor e a misericórdia. É a prova de que conheceríamos a fraternidade dentro dos limites de nossa humanidade; do contrário, seríamos Deus-Pai, o único (em uma perspectiva cristã) a compreender todas coisas.

Ambos os argumentos são bastante plausíveis, mas sua aceitação exige um certo grau de dogmatismo, necessário para aceitar-se que existe algo chamado intuição (a qual somente eu tenho acesso e mais ninguém!) e que as coisas possuem modos próprios de existir no mundo (modos que não conhecemos tão bem, do contrário não estaríamos discutindo o que é fraternidade). Ao mesmo tempo, podemos nos perguntar: o que é a fraternidade para os que não são cristãos? O que os budistas entendem por fraternidade? $\mathrm{E}$ os muçulmanos? ${ }^{24} \mathrm{E}$ os ateus? $\mathrm{E}$ os taoístas? Seria a alternativa teísta a melhor? Por outro lado, a fraternidade entendida sob uma perspectiva laica (que não tem como base o sobrenatural) deve prescindir de Deus como seu fundamento, mas não é menos problemática. Ainda não saímos do nosso estágio inicial. Segue a dúvida: O que é fraternidade? Qual seu fundamento? Estamos diante de um limite. Ou assumimos Deus como autor da criação e incluímos aí a fraternidade entre os homens (fundamento teológico) ou adotamos como parâmetro a ideia do "homem como medida de todas as coisas" (fundamento

24. Incluo aí os muçulmanos como não cristãos, embora eles entendam o islã como religião da mesma raiz do judaísmo e cristianismo: "O Islã que Muhammed havia começado a publicar depois dos 43 anos de seu nascimento, em 571, é uma verdadeira religião revelada por Alá, uma forma melhorada do judaísmo e do cristianismo, purificada de seus defeitos, posta em forma inteiramente divina e lógica, e que suprimiu as inverdades inseridas posteriormente pelas pessoas. Esta religião é o islã [...], que foi revelada a Muhammed com sua última e perfeita forma após Moisés e Jesus" (Tradução livre. Mehmet Serkan Gümüș. Islam Et Christianisme. Hakîkat Kitâbevi. (2010). Pág. 260. antropológico). Acredito que ambas as perspectivas são possíveis e legítimas.

Como resposta aos dois problemas apresentados, propomos três teses sobre a fraternidade a partir de um fundamento antropológico:

1) A distância entre a utopia e a prática da fraternidade pode ser manipulada para qualquer fim prático, inclusive contra os direitos fundamentais em um sistema democrático (discurso ideológico da fraternidade).

2) A fraternidade é frequentemente definida em função do que ela não é em si mesma, em razão de algo que a contrapõe e constitui, mas ao qual não se reduz (dialética).

3) A inclusão da fraternidade como elemento do direito pode contribuir para impedir o seu discurso ideológico (fraternidade jurídica como barreira de contenção).

\section{O ABISMO ENTRE A UTOPIA} E A PRÁTICA

Podemos distinguir a fraternidade de dois modos.

1) Entendida de modo amplo, como ideal programático para a humanidade, que se conserva ao longo do tempo, portanto, um arquétipo (in)variável (sentido utópico).

Em geral, quando falamos em fraternidade, remetemo-nos a esse uso semântico extremamente impreciso, mas que faz todo sentido do ponto de vista pragmático (afinal de contas, eu sei que ações devo adotar para ser fraterno!). O sentido utópico é impulso para um mundo melhor, necessariamente distinto do atual e que, portanto, está ligado à vontade e à esperança. Um "mundo melhor" é uma determinação de cada comunidade e constitui o aspecto variável do sentido utópico.

Sobre o uso do conceito de utopia, cabe fazer uma crítica aos que buscam distinguir "utopia" de "eutopia" com base na origem literária, histórica e etimológica do termo. Segundo essa concepção, a utopia (não lugar, lugar nenhum) seria irrealizável e, portanto, propõem a substituição pelo conceito de eutopia (realizável). Um exemplo é o texto De la Utopía hacia la Eutopía. Apuntes críticos para pensar y actuar la fraternidad hoy, de Pablo Ramírez Rivas: 
Sin embargo, considero que la utopía no ha bastado para satisfacer las necesidades que hoy tiene la humanidad. El status epistemológico de la utopía es el de marcar un rumbo, un "norte". Esta u-topia necesita hoy un giro. Mirado desde los límites, este giro implica comenzar a mirar hacia "un sur". Hacia y desde "un sur". La utopía, como es sabido, es un no lugar, un cierto "no ser": un no ha lugar. A ese no ha lugar, siempre ubicado en algún "futuro" de la modernidad emancipatoria - "libertad, igualdad..."-, le es hoy exigido una nueva superación de sí mismo: un vuelco. En los tiempos que corren, nuestros tiempos, no se trata tan sólo de aspirar a utopías. Estas no bastan. Simplemente porque no han bastado. Se trata de aspirar, imaginar y realizar eu-topias, buenos lugares o lugares de lo bueno, donde sea posible una vida decente, particular y preferencialmente para los que constituyen los límites de la Modernidad, los que están en los confines y los márgenes. ${ }^{25}$

Aparentemente, nesse processo de troca semântica, não se dão conta de que propõem uma mesma sociedade utópica, em que se muda apenas o conceito, como se a mudança no termo nome implicasse alguma concretização. De modo que não há diferença efetiva entre utopia e eutopia.

A fraternidade ainda pode ser entendida de modo estrito.

2) Constituída por um conjunto de práticas (ditas) fraternas, que mudam em função do tempo e do local e que tem como base o caráter programático utópico que lhe dá fundamento (sentido prático).

O que não tem sido percebido é que há uma distância muito grande entre o mundo ideal da utopia, sempre voltado para o porvir, e as práticas cotidianas de nossa vida em comunidade, que sempre se passam no presente. Por essa razão, não podemos afirmar que há utopia em nossa prática fraterna, embora a ela sirva de fundamento, pois a utopia deixa de ser o que é quando é realizada. A distinção entre 1 e 2 diz respeito então ao nível/esfera e à temporalidade. $\mathrm{O}$ problema da fundamentação da fraternidade decorre principalmente do abismo entre a utopia e a prática. Em face da dificuldade de fundamentar a prática, frequentemente recorre-se a posteriori ao sentido utópico

25. Osvaldo Barreneche. (Org.). Estudios Recientes SObRe FRATERNIDAD - DE LA ENUNCIACIÓN COMO PRINCIPIO A LA CONSOLIDACión COMO PERSPECTIVA. Ciudad Nueva. (2010). Pág. 83. por meio de uma petição de princípio. Quando indagadas sobre o fundamento do agir fraterno, as pessoas costumam recorrer ao argumento do mundo melhor, sem questionar-se sobre a natureza distinta do ideal e do real. Além disso, uma mesma ação fraterna pode ser fundamentada com diversos argumentos, inclusive contraditórios. O religioso pode afirmar que é fraterno para cumprir um mandamento divino; o ateu, por sua vez, pode dizer que a fraternidade é um mero dado da natureza. No exemplo, existe fraternidade tanto para o religioso quanto para o ateu, mas a explicação de sua origem é diversa. Devido a esse abismo, a fraternidade acaba por ser sempre um princípio esquecido (não só a partir da modernidade), pois nessa passagem do ideal para o real e do real para o ideal, pode-se manipular facilmente o seu sentido.

Portanto, a fraternidade não é algo "bom” de per si. Do ponto de vista do nazista, por exemplo, pode ser bastante fraterno matar judeus, assim como para o político corrupto pode ser fraterna a compra de votos que o leva ao poder. Não custa lembrar que o holocausto não deixou de acontecer em função da democracia, que já estava consolidada na Alemanha. Não estavam os arianos irmanados em sua causa? É o que ressalta Marcel David ${ }^{26}$ em seu livro Fraternité et Revolution Française, quando afirma que "De setembro de 1792 ao fim do ano II, a fraternidade se tornou uma arma de luta entre os jacobinos e os sans-culottes, que disputavam o poder."

A fraternidade não é necessariamente causa ou consequência da democracia. É produto de um discurso. Como afirma Djik ${ }^{27}$, as pessoas não são livres para falar ou escrever quando, onde, para quem, sobre o que ou como elas querem, mas são parcialmente ou totalmente controladas pelos outros, tais como o Estado, a polícia, a mídia ou uma empresa interessada na supressão da liberdade da escrita e da fala. A fraternidade é produzida nesse contexto. Por isso, vale ressaltar que a corrupção e a máfia são baseadas também em laços de família ou em verdadeiras "irmandades" políticas. A fraternidade depende inicialmente de quem eu considero irmão e dos limites do uso dessa fraternidade, que eu mesmo estabeleço. E quem manipula a fraternidade evidentemente não anuncia que o faz! Além do mais, não devemos desconsiderar que isso pode ser bastante coerente dentro de um sistema de pensamento, embora possa parecer

\footnotetext{
26. Marcel David. Fraternité et Revolution Française - 17891799. Aubier. (1987). Pág. 8.

27. Teun Van Djik. Discurso E Poder. Contexto. (2008). Pág. 18.
} 
imoral e injusto para quem dele não participa. Uma vez mais alguém pode arguir: “- Você está equivocado! Tal afirmação é incompatível com a pretensão de universalidade da fraternidade. A fraternidade nunca poderá ser utilizada para servir a interesses privados, de indivíduos ou grupos." Mas quem define o que é universal? Estamos diante de um problema milenar. Seria preciso primeiro definir o geral para podermos obter o particular. Não acreditamos que uma fundamentação dedutiva seja segura pois o sentido da premissa pode ser sempre manipulado. E é justamente isso que ocorre quando se considera seu discurso ideológico. É preciso, portanto, desenvolver uma teoria geral da fraternidade que apresente uma racionalidade que reconecte a utopia e a prática e impeça que ela seja utilizada como ideologia.

\section{A DIALÉTICA DA FRATERNIDADE}

A dialética a que nos referimos diz respeito não só ao caráter relacional da fraternidade (intersubjetividade/politicidade humana), mas a seu próprio modo de existir, expresso linguisticamente. Primeiramente, não é algo exterior a nós mesmos; é uma prática "disparada" como reação. É um movimento cujo sentido confronta algo (o outro, como alter, a pobreza, a desigualdade, o sofrimento etc.). Não há fraternidade sem esse algo que a contraponha, e que não é seu oposto, mas sim seu empecilho. Assim, é preciso um estado de coisas não fraterno para que seja possível a fraternidade. É por isso que a fraternidade não é um "viver de mãos dadas" (não seria isso a paz?). ${ }^{28} \mathrm{E}$ é justamente devido a ser constituída no diverso e na outridade que dizemos que a fraternidade é a prática do respeito, da tolerância e de tantas outras coisas que demandam uma relação. Fraternidade de um só é um contrassenso. Do ponto de vista existencial, a fraternidade atua inicialmente no encontro com o diferente, ao abrir os sujeitos para um reconhecimento do outro como outro. Esse encontro sempre ocorre, mas é a "disposição fraterna" que abre os sujeitos para uma união na diferença, em que a alteridade é ressignificada. Não há, pois, fraternidade sem essa abertura. $\mathrm{O}$ sentido de

28. Sobre esse ponto, a teoria da fraternidade tem enfatizado bastante o irmanar o outro e deixar de lado o sentir-se irmanado. Não há fraternidade sem os dois fenômenos. Não temos conhecimento sobre a existência de uma teoria específica acerca do sentimento fraterno. abertura ao outro é característico da fraternidade tanto nos pensamentos de Lubich quanto nos de Del Percio. Portanto, podemos definir fraternidade em seu sentido prático como um complexo de elementos (o algo) a ela distintos, mas a ela constitutivos, e de elementos espirituais (internos ao sujeito), sintetizados na ação (cujo sentido é dado historicamente pela cultura), que atuam no reconhecimento e ressignificação da alteridade. A dialética da fraternidade é uma concepção não ideológica de fraternidade, que busca demonstrar seu modo de funcionamento, expresso discursivamente como outros fenômenos. Claro que o agir fraterno é um fenômeno muito mais complexo, e sua análise deve envolver elementos, tais como: a racionalidade, conflito de visões de mundo, sensações, emoções e interesses.

\section{A FRATERNIDADE JURÍDICA}

A juridificação da fraternidade é possivelmente um modo eficaz de diminuir o abismo entre a utopia e a prática, na medida em que o "dizer o direito" pode validar práticas (ditas fraternas) que muitas vezes não encontram respaldo em um mundo moralmente fragmentado.

$\mathrm{Na}$ esfera do executivo, a fraternidade tem sido relacionada principalmente com a implementação de políticas públicas voltadas para a efetivação da igualdade; já no âmbito legislativo e judicial, com a dignidade da pessoa humana, ${ }^{29}$ com a ideia de mínimo existencial, solidariedade e direitos humanos. Estes têm sido os principais mecanismos para inserir a fraternidade nos ordenamentos jurídicos. Esse movimento que desloca a fraternidade da moral em direção ao direito só é possível em função de uma mudança no sentido da própria fraternidade, que é estatizada e sofre um processo de homogeneização. Esse posicionamento é, portanto, contrário ao de Del Percio $^{30}$ que acredita que a fraternidade não pode ser legislada (ordenada ou proibida) pois, como condição antropológica, já está na base do direito: "La hermandad no es del orden del derecho ni puede ser de suyo exigible legalmente, sino que es 'la ley primera'; la que da sentido, la que orienta el derecho." Como explica a seguir:

29. A relação entre fraternidade jurídica e dignidade da pessoa humana será objeto de outra investigação.

30. Enrique Del Percio, supra, nota 15. Pág. 67. 
[...] se pueden establecer normas que garanticen la libertad de expresión. $\mathrm{O}$ de movimientos, o que regulen directa o indirectamente la propiedad privada, la distribución de bienes o servicios o el acceso a información, cargos o empleos contribuyendo así a una mayor igualdad. En cambio, no es posible dictar leyes que ordenen o prohíban conductas fraternas. ${ }^{31}$

A fraternidade não poderia ser legislada porque é inescapável e está na base de toda a sociabilidade humana. Mas poderia ser reconhecida pelo Direito, o que impediria a repressão derivada do não reconhecimento de alguns sujeitos sociais. Acreditamos, entretanto, que não há impedimentos para que a fraternidade seja legislada ou utilizada como fundamento de decisões judiciais e que esteja presente não só como ideal valorativo que norteia os ordenamentos jurídicos no âmbito político. A fraternidade pode ser exigida juridicamente, ainda que admitamos que é um dado antropológico, pelo simples fato de que o seu sentido pode ser manipulado.

Quais seriam então as diferenças entre uma fraternidade moral e uma fraternidade jurídica? A principal diferença que propomos refere-se à fraternidade "moral", atributo interno aos sujeitos, enquanto a fraternidade jurídica é um atributo exterior, que conecta os dois âmbitos. Mas não apenas isso. A fraternidade jurídica não é só um direito, mas também um dever, imponível aos sujeitos e ao Estado. A fraternidade jurídica pode ser estabelecida como um conceito, um princípio ou uma regra, a depender de que função deve desempenhar e do que pretende o criador do direito em termos de modelo de sociedade a ser buscado. A fraternidade, como conceito, que aparece na arena discursiva dos fóruns jurídicos como merecedora de ser considerada direito, caminha para tornarse um princípio, um mandado de cumprimento dos direitos fundamentais, que se irradia posteriormente por meio das regras.

A fraternidade jurídica tem como vantagem evitar o discurso ideológico da fraternidade por uma classe iluminada, um discurso religioso dominante, uma teoria dos oprimidos libertários ou qualquer grupo que tente impor sua própria concepção de mundo. Nesse sentido, o direito fraterno oferece um filtro que ajuda a impedir um abuso na reivindicação de direitos e deveres, com fundamento na fraternidade.

31. Id. Pág. 63.
Um direito fraterno encontra como pressuposto a fraternidade moral, sem a qual não pode existir. Por isso que ser fraterno em sentido jurídico demanda obter primeiro uma resposta à primeira pergunta que nos norteia: como ser fraterno se não sei o que é fraternidade? Daí a importância de estudos sobre a fraternidade, que estabeleceriam os limites ao seu exercício no âmbito moral, e sobre fraternidade jurídica, que indicariam os limites dessa prática no âmbito dos ordenamentos jurídicos. A fraternidade jurídica é, portanto, inscrita na especificidade de cada direito nacional (mas também do direito internacional), submetida à avaliação e a critérios dos mecanismos jurídicos disponíveis (doutrinários, judiciais, legislativos etc.), que modulam seu significado e seu alcance no exercício do controle social. Não devemos esperar que o direito altere sua racionalidade em virtude da inclusão da fraternidade como elemento jurídico, o que muda são os seus objetivos e o sentido de suas práticas.

\section{CONCLUindo, MAS NÃO FINALIZANDO}

A fraternidade jurídica não deveria nos surpreender como sendo algo muito distante da fraternidade em seu sentido usual. Isso porque o direito sempre se encontra em uma relação difícil com a realidade, em uma luta constante entre aquilo que ele é, deve ser e o ser do mundo natural em que vive o homem. O direito não toma impunemente elementos da cultura (igualdade, liberdade, trabalho, honra, dignidade etc.). O preço que se paga é o da necessidade de fixar o significado jurídico de cada um desses elementos, o que normalmente é um grande desafio ante a diversidade de casos concretos relacionados. $\mathrm{O}$ mesmo ocorre com a fraternidade. Se se propõe que ela seja direito, a primeira coisa que devemos considerar é uma perda relativa da autonomia da sociedade em definir, mesmo que o faça precariamente, o que considera fraternidade, em favor de uma massificação do sentido que possibilita seu cumprimento como norma jurídica. Em segundo lugar, que é possível manipular a fraternidade como direito, havendo como consequência o aprofundamento do abismo entre o ideal e o real, por via da manipulação de seu sentido jurídico e sentido moral. Isso constitui o discurso ideológico da fraternidade jurídica. 
Em resumo, foram apresentadas as duas principais teorias da fraternidade já desenvolvidas. Segundo essas teorias, a fraternidade seria desejável em qualquer sociedade, o que nos faz pensar se não seria esta uma boa alternativa para uma sociedade pós-neoliberal. As teorias de Lubich e Enrique Del Percio são ao mesmo tempo antropológicas (ao definir o humano) e idealistas, no sentido normativo. A principal diferença entre elas é fundamento, teológico em Lubich e não teológico no pensamento de Del Percio. Entretanto, as duas têm como fundo comum a defesa de pontos de vista políticos que precedem as próprias teorias.

Observamos também que, quanto à explicação sobre a origem, a fraternidade pode ter basicamente dois fundamentos: 1) a criação divina (fundamento teológico); 2) a criação humana (fundamento antropológico). Partir de um fundamento não teológico possibilita pensarmos a fraternidade de modo não naturalista, o que representa uma ruptura com a ideia da fraternidade como algo sempre positivo do ponto de vista da moralidade dominante.

Concluímos que há uma espécie de abismo entre a fraternidade em seu sentido utópico (ideal) e seu sentido prático (real). O sentido utópico é tomado como fundamento do sentido prático e pode ser manipulado discursivamente para qualquer fim prático. Denominamos isso de "discurso ideológico da fraternidade".

Posteriormente, vimos que a dialética explica a fraternidade a partir da ideia de "abertura fraterna", um fenômeno existencial que atua no reconhecimento dos sujeitos e na ressignificação da alteridade. Segundo essa perspectiva, a fraternidade, discursivamente, é algo sendo outras. Passamos então à tese principal deste artigo: a inclusão da fraternidade como elemento jurídico pode ajudar a impedir o discurso ideológico do próprio direito (quando este se volta contra os direitos fundamentais) e servir como barreira de contenção ao discurso ideológico da fraternidade moral, embora haja sempre o risco de esta ser utilizada para aprofundar o abismo entre a utopia e a prática, tornando-se um mecanismo jurídico de opressão social.

Obviamente, muitos argumentos presentes neste trabalho precisam ser mais bem explorados e explicados. Nossa intenção foi repensar o fenômeno da fraternidade partindo das duas principais teorias sobre a fraternidade à luz da busca por um modelo melhor de sociedade. Algumas perguntas devem persistir: Como ser fraterno se eu não sei o que é fraternidade? É possível um uso discursivo não ideológico e retórico da fraternidade moral e jurídica?

\section{REFERÊNCIAS}

Antônio Maria Baggio (org.). O PRINCíPIo EsQUeCIDO: EXIGÊNCIAS, RECURSOS E DEFINIÇÕES DA FRATERNIDADE NA POLí́tiCA. Cidade Nova. (2008).

Bertrand Russell. Ensaios CÉTICOS. L \& PM. (2014).

Chiara Lubich. Essential writings. Spirituality. Dialogue. Culture. New City Press. (2007).

Emir Sader. Refundar el Estado. Posneoliberalismo en AmÉrica Latina. Instituto de Estudios y Formación de la CTA. (2008).

Enrique Del Percio. Ineludible Fraternidad CONFLICTO, PODER Y DESEO. Ciccus. (2014).

Ernst Tugendhat. InTRODUCCión A LA FILOsofía ANALÍTICA. Gedisa. (2003).

Jamie Peck. Nik Theodore e Neil Brenner. Mal-estar no Pósneoliberalismo. Novos Estudos - CEBRAP 92. Marzo de 2012.

Jean-Luc Ferry. A REVOLUÇão DO AMOR: POR UMA ESPIRITUALIDAde LaICA. Trad. Véra Lucia dos Reis. Objetiva. (2012).

João Maurício Adeodato. A RetóRica Constitucional - SOBRE TOLERÂNCIA, DIREITOS HUMANOS E OUTROS FUNDAMENTOS ÉTICOS DO DIREITO POSITIVO. Saraiva. (2009).

Marcel David. Fraternité et Revolution Française 1789-1799. Aubier. (1987).

Marconi Andrade Silva, Fernando Gomes Andrade e Paulo MunizLopes(Orgs.).Cidadania, ParticipaÇãoe FraTERNIDADE - UMA ABORDAGEM MULTIDISCIPLINAR. Editora UFPE. (2014).

Maria Voce. Desafios. Cidade Nova. (2014).

Mehmet Serkan Gümüş. IsLAm et Christianisme. Hakîkat Kitâbevi. (2010).

Mônica Nicknich. A fraternidade como valor orientativo dos novos direitos na posmodernidade. Antônio Maria Baggio (Org.). O PRINCÍPIO ESQUECIDO: EXIGÊNCIAS, RECURSOS E DEFINIÇÕES DA FRATERNIDADE NA POLÍTICA. Cidade Nova. (2008).

Osvaldo Barreneche (Org.). Estudios Recientes sobre FRATERNIDAD - DE LA ENUNCIACIÓN COMO PRINCIPIO 
A LA CONSOlidación como Perspectiva. Ciudad Nueva. (2010).
Teun Van Djik. Discurso E PODER. Contexto. (2008).

Thomas Piketty. O CAPITAL NO SÉCULO XxI. Intrínseca. (2014) 